University of South Carolina

Scholar Commons

$11-12-2015$

\title{
Size-Controlled Large-Diameter and Few-Walled Carbon Nanotube Catalysts for Oxygen Reduction
}

Xianliang Wang

Qing Li

Hengyu Pan

Ye Lin

University of South Carolina - Columbia, linye@mailbox.sc.edu

Yujie Ke

See next page for additional authors

Follow this and additional works at: https://scholarcommons.sc.edu/emec_facpub

Part of the Catalysis and Reaction Engineering Commons, and the Mechanical Engineering Commons

\section{Publication Info}

Published in Nanoscale, Volume 7, Issue 47, 2015, pages 20290-20298.

(C) Nanoscale, 2015, Royal Society of Chemistry

Wang, X., Li, Q., Pan, H., Lin, Y., Ke, Y., Sheng, H., Swihart, M. T., Wu, G. (2015). Size-Controlled LargeDiameter and Few-Walled Carbon Nanotube Catalysts for Oxygen Reduction. Nanoscale, 7(47),

20290-20298.

http://dx.doi.org/10.1039/C5NR05864C

This Article is brought to you by the Mechanical Engineering, Department of at Scholar Commons. It has been accepted for inclusion in Faculty Publications by an authorized administrator of Scholar Commons. For more information, please contact digres@mailbox.sc.edu. 


\section{Author(s)}

Xianliang Wang, Qing Li, Hengyu Pan, Ye Lin, Yujie Ke, Haiyang Sheng, Mark T. Swihart, and Gang Wu 


\title{
Nanoscale
}

\section{PAPER}

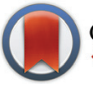

CrossMark \& click for update

Cite this: Nanoscale, 2015, 7, 20290

\section{Size-controlled large-diameter and few-walled carbon nanotube catalysts for oxygen reduction $\uparrow$}

\author{
Xianliang Wang, ${ }^{a}$ Qing Li, ${ }^{b}$ Hengyu Pan, ${ }^{a}$ Ye Lin, ${ }^{c}$ Yujie Ke, ${ }^{a}$ Haiyang Sheng, ${ }^{a}$ \\ Mark T. Swihart*a and Gang Wu*a
}

\begin{abstract}
We demonstrate a new strategy for tuning the size of large-diameter and few-walled nitrogen-doped carbon nanotubes ( $\mathrm{N}$-CNTs) from 50 to $150 \mathrm{~nm}$ by varying the transition metal ( $\mathrm{TM}=\mathrm{Fe}, \mathrm{Co}, \mathrm{Ni}$ or $\mathrm{Mn}$ ) used to catalyze graphitization of dicyandiamide. Fe yielded the largest tubes, followed by $\mathrm{Co}$ and $\mathrm{Ni}$, while $\mathrm{Mn}$ produced a clot-like carbon morphology. We show that morphology is correlated with electrocatalytic activity for the oxygen reduction reaction (ORR). A clear trend of $\mathrm{Fe}>\mathrm{Co}>\mathrm{Ni}>\mathrm{Mn}$ for the ORR catalytic activity was observed, in both alkaline media and more demanding acidic media. The Fe-derived $\mathrm{N}$-CNTs exhibited the highest BET $\left(\sim 870 \mathrm{~m}^{2} \mathrm{~g}^{-1}\right)$ and electrochemically accessible $\left(\sim 450 \mathrm{~m}^{2} \mathrm{~g}^{-1}\right)$ surface areas and, more importantly, the highest concentration of nitrogen incorporated into the carbon planes. Thus, in addition to the intrinsic high activity of Fe-derived catalysts, the high surface area and nitrogen doping contribute to high ORR activity. This work, for the first time, demonstrates size-controlled synthesis of large-diameter N-doped carbon tube electrocatalysts by varying the metal used in N-CNT generation. Electrocatalytic activity of the Fe-derived catalyst is already the best among studied metals, due to the high intrinsic activity of possible Fe-N coordination. This work further provides a promising route to advanced Fe-N-C nonprecious metal catalysts by generating favorable morphology with more active sites and improved mass transfer.
\end{abstract}

Received 27th August 2015 Accepted 11th November 2015

DOI: $10.1039 /$ c5nr05864c

www.rsc.org/nanoscale lity compared to other NPMC formulations. ${ }^{1,3,13-19}$ According to other researchers and ourselves, ${ }^{20-28}$ in situ formation of graphitized carbon nanostructures in the $\mathrm{M}-\mathrm{N}-\mathrm{C}$ catalysts is a critical factor dictating active site generation and is linked to the measured ORR activity. The currently prepared carbon nanostructures in $\mathrm{M}-\mathrm{N}-\mathrm{C}$ catalysts include tubes, onion-like carbon, and platelets (multi-layered graphene). ${ }^{23,24,26}$ They can be well controlled by carefully choosing the nitrogencarbon and transition metal precursors and processing methods. ${ }^{25-28}$ The studied nitrogen-carbon precursors included polyaniline, ethylenediamine, melamine, and cyanamide. ${ }^{3,5,13,26}$ A more specific hypothesis to explain the role of carbon structures in catalysts is that they may serve as a matrix for hosting active nitrogen or metal moieties.

Recently, we discovered a new method to prepare N-doped carbon tubes with large diameters and relatively thin walls (less than 10 layers). ${ }^{20}$ Although the large-diameter and fewwalled tubes contain multiple carbon layers, their wall thickness and ratio of wall thickness to tube diameter are very small compared to conventional multi-walled carbon nanotubes (MWNTs). ${ }^{21-23}$ As a result, their surface areas are much higher than conventional MWNTs. In addition, the large diameter provides a mesoporous structure that facilitates mass transfer into and out of the tubes. Thus, these novel carbon nanotubes provide a new opportunity to develop high-performance 
NPMCs for the ORR. In a previous effort, we focused on optimization of the activity by using metal-organic frameworks (MOFs) as templates. ${ }^{20}$ In this work, as a replacement for expensive MOFs, a carbon black, BlackPearl 2000, was used to prepare the tube-like catalysts. Importantly, we observed the size-dependence of the carbon nanotubes produced using different TMs including $\mathrm{Ni}, \mathrm{Co}, \mathrm{Fe}$, and $\mathrm{Mn}$, with a low-cost precursor (e.g., dicyandiamide, price: $\$ 1-2 \mathrm{~kg}^{-1}$ ). The tube diameter and level of nitrogen incorporation correlate directly with the measured catalytic activity for the ORR. Although many studies have explored the role of TMs in NPMC preparation, few reports have systematically correlated the choice of metal, resulting morphologies, and catalyst properties. Herein, we discovered the morphology and chemical doping of carbon nanotubes can be fine-tuned by selection of the TM used in their preparation. This, in turn, provides control of electrochemical properties and catalytic activity. Fe-derived carbon nanotubes have the largest diameter, followed by Co- and $\mathrm{Ni}$ derived ones. While the detailed mechanism through which the TM controls the tube size remains uncertain, we show that the TM choice plays a significant role in NPMC preparation, influencing key catalyst properties including morphology, surface area, elemental composition, and ORR activity. Thus, this work provides a new path toward development of highperformance carbon-based NPMCs by controlled formation of favorable nanocarbon structures.

\section{Experimental section}

\section{Catalyst synthesis}

Large-diameter and few-walled nitrogen-doped carbon nanotubes (N-CNTs) were prepared by first mixing 24 mmol dicyandiamide with $6 \mathrm{mmol}$ of one of the metal acetates $\left(\mathrm{MAc}_{x}, \mathbf{M}=\right.$ $\mathrm{Fe}, \mathrm{Co}, \mathrm{Ni}$ or $\mathrm{Mn}$ ) in $250 \mathrm{~mL}$ ethanol. The solution was heated to $78{ }^{\circ} \mathrm{C}$ in a covered $2 \mathrm{~L}$ Erlenmeyer flask and held at this temperature for $5 \mathrm{~h}$. Next, $0.2 \mathrm{~g}$ BlackPearl 2000 carbon black was added and the mixture was stirred for an additional $24 \mathrm{~h}$ before uncovering the flask and allowing the solvent to evaporate. The resulting dry powder was heated to $1000{ }^{\circ} \mathrm{C}$ for $1 \mathrm{~h}$ in a tube furnace under a constant $\mathrm{N}_{2}$ flow of $50 \mathrm{~mL} \mathrm{~min}^{-1}$. The heat-treated sample was then suspended in $0.5 \mathrm{M} \mathrm{H}_{2} \mathrm{SO}_{4}$ at $80^{\circ} \mathrm{C}$ for 5 hours to remove unstable metal species. Finally, a second heat treatment, at $1000{ }^{\circ} \mathrm{C}$ for $3 \mathrm{~h}$, was carried out to remove the functional groups and oxidative carbon layers in the catalysts to further improve the ORR activity.

\section{Physical characterization}

The size and morphology of catalysts were characterized using transmission electron microscopy (TEM) on a JEOL JEM-2010 or a JEOL $2100 \mathrm{~F}$ microscope at a working voltage of $200 \mathrm{kV}$. Samples were prepared for imaging by drop casting a dilute suspension of the catalyst onto a carbon-coated TEM grid. Catalyst morphology was also studied using scanning electron microscopy (SEM) on a Hitachi SU 70 microscope at a working voltage of $5 \mathrm{kV}$. The crystalline phases present in each sample were identified using powder X-ray diffraction (XRD) on a Rigaku Ultima IV diffractometer with $\mathrm{Cu} \mathrm{K}-\alpha$ X-rays. X-ray photoelectron spectroscopy (XPS) was performed using a Kratos AXIS Ultra DLD XPS system equipped with a hemispherical energy analyzer and a monochromatic Al Ko source. The monochromatic $\mathrm{Al} \mathrm{K \alpha}$ source was operated at $15 \mathrm{keV}$ and $150 \mathrm{~W}$; pass energy was fixed at $40 \mathrm{eV}$ for the high resolution scans. All samples were prepared as pressed powders supported on a metal bar for the XPS measurements. BrunauerEmmett-Teller (BET) surface area was measured using $\mathrm{N}_{2}$ adsorption/desorption at $77 \mathrm{~K}$ on a Micromeritics TriStar II. Samples were pre-treated at $150{ }^{\circ} \mathrm{C}$ for $3 \mathrm{~h}$ under vacuum prior to nitrogen physisorption measurements.

\section{Electrochemical measurements}

All electrochemical measurements were performed using a CHI Electrochemical Station (Model 760b) in a conventional three-electrode cell at room temperature. A glassy carbon rotating disk electrode (GC-RDE) was used as the working electrode. Each catalyst was mixed with isopropanol and a Nafion solution to produce an ink that was drop-cast onto the GC-RDE and air-dried for $30 \mathrm{~min}$ at $60{ }^{\circ} \mathrm{C}$. The catalyst-coated GC-RDE was subjected to cyclic voltammetry (CV) in $\mathrm{N}_{2}$-saturated $0.5 \mathrm{M}$ $\mathrm{H}_{2} \mathrm{SO}_{4}$ electrolyte at a scan rate of $20 \mathrm{mV} \mathrm{s}^{-1}$ to determine the electrochemically accessible surface area. Then, to measure the electrocatalytic activity for the ORR, rotating ring disc electrode (RRDE) measurements were performed in $\mathrm{O}_{2}$-saturated $0.5 \mathrm{M} \mathrm{H}_{2} \mathrm{SO}_{4}$ and in $0.1 \mathrm{M} \mathrm{NaOH}$ at room temperature and a rotation rate of $900 \mathrm{rpm}$. A graphite rod was used as the counter electrode. An $\mathrm{Hg} / \mathrm{HgSO}_{4}\left(\mathrm{~K}_{2} \mathrm{SO}_{4}\right.$-sat., $0.705 \mathrm{~V}$ vs. RHE) or an $\mathrm{Ag} / \mathrm{AgCl}$ electrode (KCl-sat., $0.996 \mathrm{~V}$ vs. RHE) was employed as the reference electrode in acidic and alkaline electrolytes, respectively. The loading of catalyst was controlled at $800 \mu \mathrm{g} \mathrm{cm}^{-2}$ for all measurements. ORR steady-state polarization curves were recorded using discrete potential steps of $0.05 \mathrm{~V}$ at intervals of $30 \mathrm{~s}$ from $1.0 \mathrm{~V}$ to $0 \mathrm{~V} v s$. RHE.

\section{Results and discussion}

\section{Controlled morphologies and structures}

We developed a facile and low-cost synthesis strategy to prepare a new type of large-size and few layered tube catalysts by using various metals, dicyandiamide, and Blackpearl 2000 carbon black. The tube size can be controlled via the choice of metal (Fe, Co, or Ni). The Fe-derived tube catalyst exhibits the largest size followed by $\mathrm{Co}-$ and $\mathrm{Ni}$-derived ones as evidenced by direct SEM image observation (Fig. 1). Synthesis using Fe, Co or Ni yielded highly graphitized tubes with bamboo-like structures. Based upon measurement of approximately 35 tubes from each sample, the Fe-derived carbon nanotubes exhibited the largest average diameter (Fig. 1a,b and $\mathrm{S} 1 \dagger$ ), $112 \mathrm{~nm}$, while the tubes derived from Co and Ni had average diameters of 61 and $42 \mathrm{~nm}$, respectively (Fig. 1c,d and S1†).

Prior work suggests that the growth of carbon nanotubes is based on the chemical interaction of $\pi$ electrons of graphite 

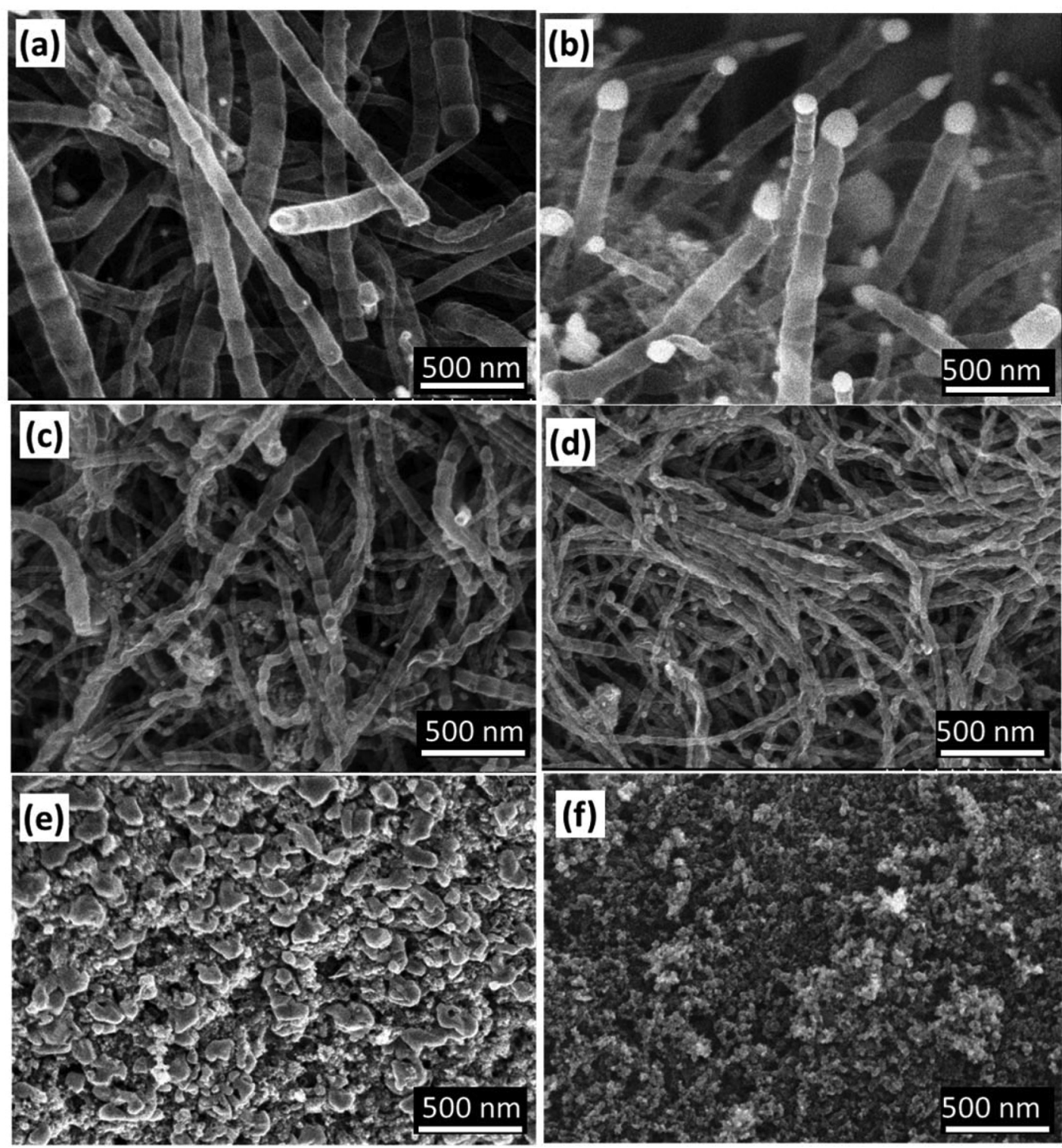

Fig. 1 SEM images of carbon catalysts prepared using: (a) Fe, (b) Fe but before acid leaching treatment, (c) Co; (d) Ni; (e) Mn; (f) no TM. The mean diameters of the tubes prepared using each metal were $(a, b) F e(112 \mathrm{~nm})$, (c) Co $(61 \mathrm{~nm})$, and (d) Ni (42 nm). Diameter distributions are provided in ESI, Fig. S1.†

with 3d-electrons of the TMs. ${ }^{29}$ Thus, the formation of metal (Fe, Co or Ni) nanoparticles by reduction of the metal salts is expected to initiate the formation of carbon nanotubes. We believe the growth mechanism of carbon nanotubes is similar to that of traditional carbon nanotubes. The tip-growth mechanism is clearly evidenced by SEM images like Fig. 1b, showing Fe-derived tubes with metal particles attached at the tips of the tubes prior to acid leaching.

Additional images showing the typical morphology of Federived carbon nanotubes are provided in Fig. S2, $\uparrow$ illustrating the highly porous and 3D carbon nanotube network architecture generated by this synthesis process. Notably, the diameter of Fe-derived carbon nanotubes (up to $150 \mathrm{~nm}$ ) was significantly larger than the size of traditional $\mathrm{N}$-doped carbon nano- tubes prepared by CVD methods (usually less than $50 \mathrm{~nm}) .{ }^{30-34}$ Tang et al. ${ }^{34}$ employed a CVD method to prepare $\mathrm{N}$-doped carbon nanotubes using nanowire templates. The $\mathrm{N}$-CNT growth method demonstrated here is also much simpler and lower cost than traditional CVD. ${ }^{34,35}$ The unique capability to tune the tube size over a wide range by varying type of metals (e.g., $\mathrm{Fe}, \mathrm{Co}$, and $\mathrm{Ni}$ ) was discovered, which further influences the ORR activity of the corresponding catalysts. The trend of increasing tube diameter with decreasing atomic number of the TM did not continue for Mn. As shown in Fig. 1e, irregular clot-like structures were generated, rather than carbon nanotubes. Fig. If shows carbon materials synthesized under identical conditions in the absence of any metal. No features other than those associated with the Black- 

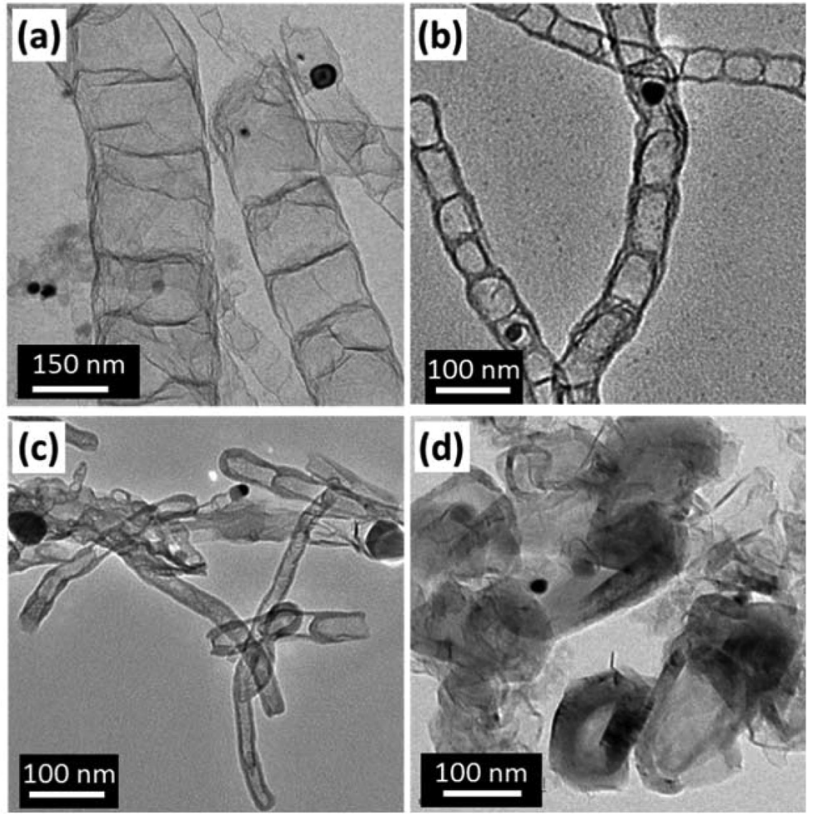

Fig. 2 TEM images of carbon nanotubes or clots with different size and morphologies synthesized using various transition metals: (a) $\mathrm{Fe}$, (b) $\mathrm{Co}$, (c) $\mathrm{Ni}$, and (d) $\mathrm{Mn}$

pearl carbon particles were observed, suggesting that no significant amount of highly graphitized nanocarbon forms in the absence of metal.

The morphologies of carbon nanotubes were further studied by TEM imaging (Fig. 2). In good agreement with SEM results, a clear trend of tube size was observed in the sequence $\mathrm{Fe}>\mathrm{Co}>\mathrm{Ni}$. In addition, Mn-derived nanocarbon exhibited a hollow, irregular, quasi-spherical carbon particle morphology. This observation is consistent with prior studies of nucleation and growth of carbon nanotubes using TM catalysts. Overall, the most active catalysts for carbon nanotube formation are Fe, Co and Ni. Furthermore, HR-TEM images shown in Fig. 3 were further used to reveal the subtle structures of carbon nanotubes and nanoshells observed in Fe- and Mn-derived samples, respectively. Unlike traditional carbon nanotubes with continuous hollow structures, these ultra-large diameter carbon nanotubes present bamboo-like morphologies, in which a number of cages are connected continuously (Fig. 3a). The wall thickness of a typical carbon tube was 6-10 layers of carbon planes (Fig. 3b). The term "few-walled" is used in this work to describe graphitic structures with few layers (less than 10 layers). ${ }^{30}$ Thus, we refer to these large carbon tubes as fewwalled carbon nanotubes. Notably, the carbon layers in the carbon nanotube exhibit substantial defects such as vacancies and dislocations, which can be beneficial for electrocatalysis. In good agreement with the observation in Fig. 1b, during the formation of carbon nanotubes, carbon shells are growing along the metallic agglomerates and ultimately encapsulate some of them. Rather than the bamboo-like carbon nanotubes derived from Fe, isolated carbon cages were observed in the
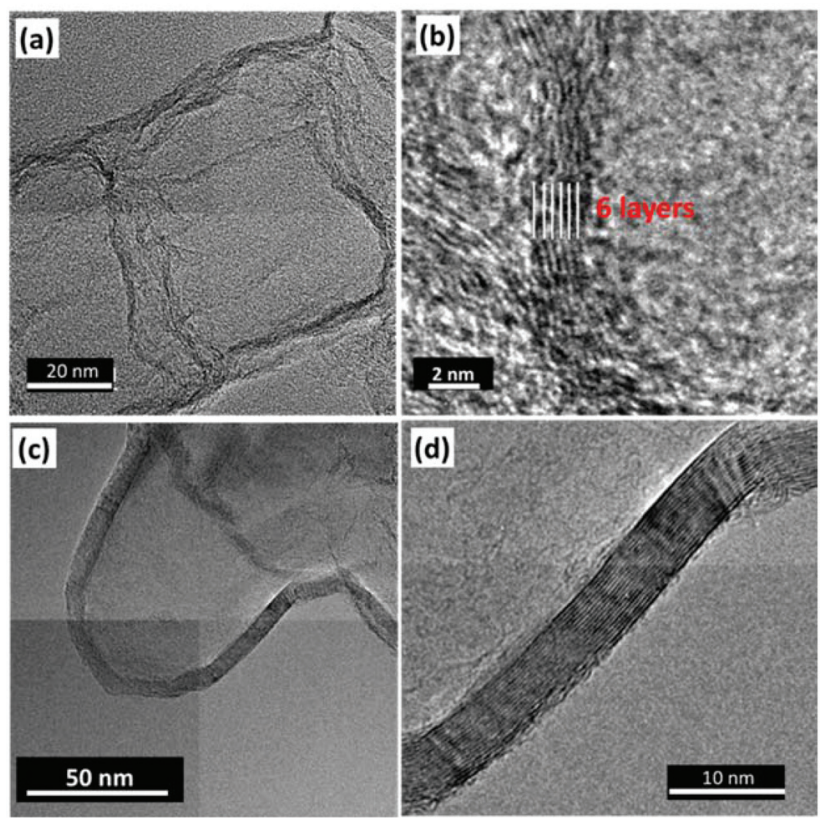

Fig. 3 HR-TEM images revealing the subtle structures of carbon nanotubes and nanoshells derived from Fe $(a-b)$ and $M n(c-d)$.

Mn-derived sample as shown in Fig. 3c. Notably, well-defined and highly ordered carbon layer structures were produced in the presence of Mn (Fig. 3d).

These TEM imaging results suggest that $\mathrm{Mn}$ is highly effective in catalyzing the graphitization of carbon precursors (i.e. dicyandiamide) during the high temperature treatment. However, lack of defects in the ordered carbon structures can be a disadvantage for electrocatalysis and may significantly limit the electrocatalytic activity. These structural observations are in good agreement with the much lower doping level of nitrogen and low activity for the ORR measured with the Mnderived samples discussed below. ESI Fig. S3A-D† show the dependence of tube morphology upon heating temperature. We found that $700{ }^{\circ} \mathrm{C}$ is the minimum temperature required for the formation of tubes, and further increasing the temperature from $700{ }^{\circ} \mathrm{C}$ to $1000{ }^{\circ} \mathrm{C}$ increased the yield of material with tube morphology, suggesting higher temperature is more favorable the tube growth. The dependence of ORR activity upon the heating temperatures during the synthesis was studied for the best performing Fe-based catalysts (Fig. S4 $\dagger$ ). The sample treated at $1000{ }^{\circ} \mathrm{C}$ showed the highest activity in both acidic and alkaline electrolytes. Although previous studies have reported production of nitrogen-doped carbon catalysts with tunable physical and chemical properties, ${ }^{35,36}$ here we provide the first demonstration that the diameter of carbon tubes can be manipulated by varying the TM used in the precursor mixture. Given the important role played by the TM in controlling nanocarbon morphology, we anticipate similarly strong effect on the catalytic properties of these nanocarbons. 


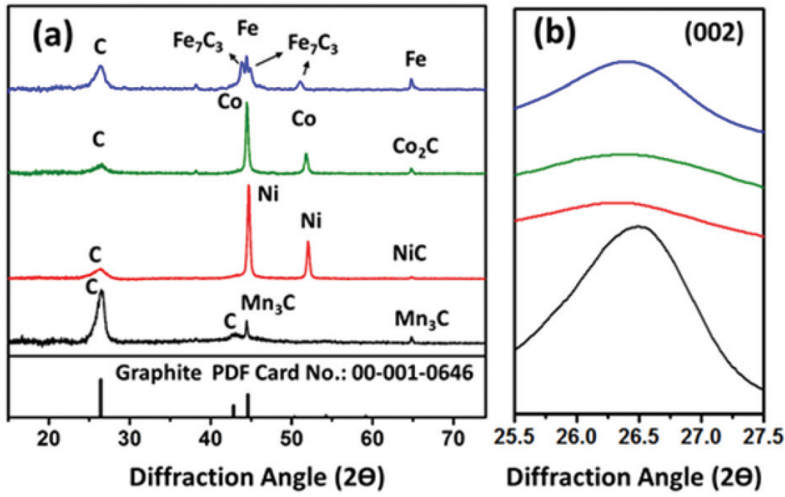

Fig. 4 (a) XRD patterns of carbon nanotubes or clots synthesized using various metals: $\mathrm{Mn}$ (black curve), $\mathrm{Ni}$ (red curve), $\mathrm{Co}$ (green curve) and $\mathrm{Fe}$ (blue curve). (b) Enlarged view of the (002) peaks.

Powder XRD (Fig. 4a) showed the presence of graphitic carbon, metal carbides, and metals in each of the carbon nanotube samples only subjected to the first treatment and before acidic leaching. The diffraction peak near $2 \theta=26.5^{\circ}$, assigned to the (002) plane of graphitic carbon, is present in all samples. The enlarged view of these peaks in Fig. $4 \mathrm{~b}$ shows a slight shift to lower diffraction angles following the trend of $\mathrm{Fe}<\mathrm{Co} \approx \mathrm{Ni}<\mathrm{Mn}$. The fact that the Fe-derived sample exhibits the largest shift, $0.1^{\circ}$, implies that it has the largest lattice constant among the samples. In the case of Fe-derived carbon nanotubes, the $\mathrm{XRD}$ peaks at $43.6^{\circ}, 45.0^{\circ}$ and $51.0^{\circ}$ were assigned to iron carbide $\left(\mathrm{Fe}_{7} \mathrm{C}_{3}\right)$ and the peaks at $44.5^{\circ}$ and $64.7^{\circ}$ are attributed to metallic Fe. In the XRD patterns for Co and Ni-derived carbon nanotubes, metallic $\mathrm{Co}$ and $\mathrm{Ni}$ were identified, along with small amounts of $\mathrm{Co}_{2} \mathrm{C}$ and NiC. The XRD pattern of the Mn-derived sample showed the presence of $\mathrm{Mn}_{3} \mathrm{C}$ but no metallic $\mathrm{Mn}$ in the final product. These observations suggest that the metallic species (e.g. Fe, Co and $\mathrm{Ni}$ ) may be important for generating a large-diameter tube morphology during the high-temperature graphitization process.

\section{Nitrogen doping}

Nitrogen doping into nanocarbon electrocatalysts has been hypothesized by many to be important to their ORR activity. We employed XPS to systematically study the effect of the TM on the level and position of nitrogen doping in these nanocarbon samples. Results are summarized in Table 1. The

Table 1 Summary of elemental composition of catalysts produced using various transition metals

\begin{tabular}{llllll}
\hline & \multicolumn{3}{l}{ Atomic concentration at \% } & \\
\cline { 2 - 4 } $\begin{array}{l}\text { Transition } \\
\text { metal catalyst }\end{array}$ & $\mathrm{M}$ & $\mathrm{C}$ & $\mathrm{O}$ & $\mathrm{N}$ & $\begin{array}{l}\text { Graphitic/pyridinic } \\
\text { N ratio }\end{array}$ \\
\hline $\mathrm{Fe}$ & 0.4 & 90.4 & 4.7 & 4.5 & $54 / 46$ \\
$\mathrm{Co}$ & 1.2 & 90.3 & 4.3 & 4.2 & $54 / 46$ \\
$\mathrm{Ni}$ & 1.4 & 91.4 & 3.3 & 3.9 & $55 / 45$ \\
$\mathrm{Mn}$ & 0.1 & 96.3 & 1.8 & 1.8 & $60 / 40$
\end{tabular}

$\mathrm{N}$ content in the carbon nanotubes derived from $\mathrm{Fe}$ is the highest (4.49 at\%), followed by Co (4.22 at\%), Ni (3.86 at\%), and $\mathrm{Mn}$ (1.78 at\%). This trend is consistent with the shifts of the (002) peaks observed in the XRD patterns. The peak position shifts to lower angle with increased N-doping, suggesting that higher nitrogen doping produces a larger $d$-spacing between graphite layers. In addition, elemental analysis showed that traces of metal remained in these carbon nanotube samples. During the leaching treatment with $0.5 \mathrm{M}$ $\mathrm{H}_{2} \mathrm{SO}_{4}$ at $80{ }^{\circ} \mathrm{C}$ for 5 hours, those metallic species that are fully enclosed by carbon shells are inaccessible to the acid and are not removed. The residual content of $\mathrm{Ni}$ in the nanocarbon was higher than that of $\mathrm{Co}$ and $\mathrm{Fe}(\mathrm{Ni}>\mathrm{Co}>\mathrm{Fe})$. The amount of residual metal species in the carbon nanotubes decreased with increasing tube diameter. This suggests that leaching out the metal residues from the smaller tubes is more difficult than from larger tubes, which is reasonable. Prior studies have proven that such metal species are inactive for the ORR, especially in acidic electrolyte. ${ }^{26,37}$ Thus, removal of these inactive species can increase the activity and enhance the stability of the nanocarbon electrocatalysts.

We also analyzed high-resolution N 1s XPS spectra (Fig. 5) to determine the chemical state of the nitrogen dopant in these nanocarbons. Each sample featured two dominant nitrogen peaks at 401.2 and $398.7 \mathrm{eV}$. These can be assigned to graphitic and pyridinic nitrogen, respectively. This suggests that nitrogen atoms are doped both within the carbon planes (graphitic) and at the edges (pyridinic). ${ }^{38-40}$

Nitrogen atoms can be regarded as n-type dopants in carbon, and have been associated with high ORR activity. ${ }^{41-43}$ The ratio of graphitic nitrogen to pyridinic nitrogen (Table 1) has been considered to be an important factor in determining the ORR catalytic activity. ${ }^{44}$ The graphitic nitrogen content in Mn-derived carbon clots $(60 \%)$ is notably higher than that in
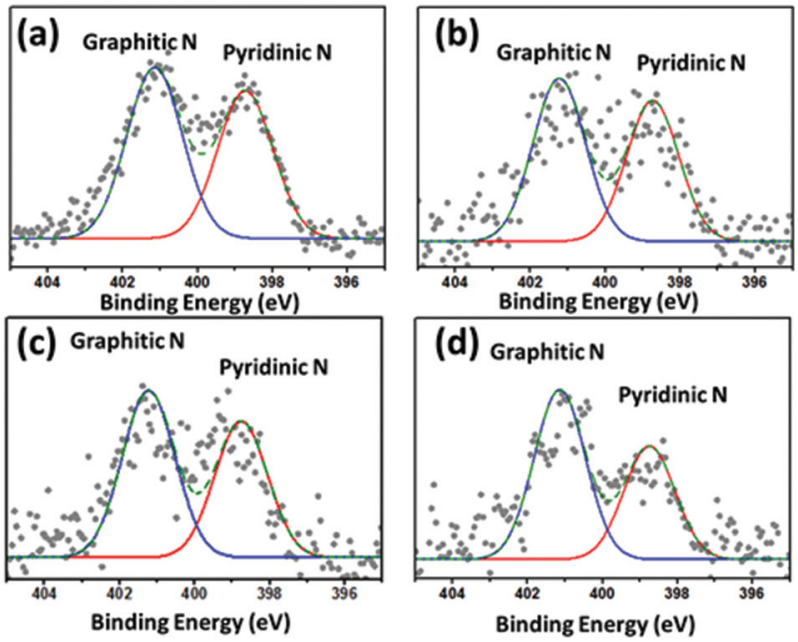

Fig. 5 High resolution XPS spectra of the $\mathrm{N}$ 1s region for the samples synthesized using (a) $\mathrm{Fe}$, (b) $\mathrm{Co}$, (c) $\mathrm{Ni}$, (d) $\mathrm{Mn}$. Spectra were deconvoluted into two peaks, as shown. 
$\mathrm{Fe}$, Co and Ni-derived carbon nanotubes, which were all nearly identical (54-55\%). In ESI Fig. S5 $\dagger$ it compares the XPS spectra of $\mathrm{C}$ 1s for the samples derived from $\mathrm{Fe}, \mathrm{Co}, \mathrm{Ni}$ and Mn. Overall, the broad peak can be decomposed into three components. The sharp peak at $284.7 \mathrm{eV}$ can be assigned to the $\mathrm{C}-\mathrm{C}$ bonds in graphitic carbon structures. The full width at half-maximum (FWHM) of Mn-derived carbon clots was $1.10 \mathrm{eV}$, which was smaller than carbon nanotubes derived from Fe (1.25 eV), Co (1.25 eV), and Ni (1.20 eV). The comparison of C 1s spectra suggests a relatively high degree of graphitization in the Mn-derived nanocarbon. This result is consistent with its XRD pattern, which showed the sharpest (002) peak among the nanocarbons studied here. The peak at $286.2 \mathrm{eV}$ is assigned to $\mathrm{C}-\mathrm{O}$. The largest $\mathrm{C}-\mathrm{O}$ content was observed in $\mathrm{Fe}-$ derived catalysts, consistent with its relatively high oxygen content, as shown in Table 1 . These samples all showed a very small contribution from $\mathrm{C}=\mathrm{O}$ at higher binding energy, near $288.1 \mathrm{eV}$.

\section{BET and electrochemical surface areas}

In addition to nitrogen doping, the ORR activity is strongly influenced by the nanocarbon morphology, including its surface area and pore size distribution. Thus, BET surface areas of these nanocarbons were measured using $\mathrm{N}_{2}$ physisorption at $77 \mathrm{~K}$. The measured surface areas as function of the metal used for the synthesis are shown in Fig. S6. $\dagger$ The Fe-derived carbon nanotube sample, which showed the largest tube diameters, also exhibited the highest surface area $\left(868 \mathrm{~m}^{2} \mathrm{~g}^{-1}\right)$, followed by the nanocarbons derived from Co $\left(466 \mathrm{~m}^{2} \mathrm{~g}^{-1}\right)$, Ni $\left(391 \mathrm{~m}^{2} \mathrm{~g}^{-1}\right)$, and $\mathrm{Mn}\left(167 \mathrm{~m}^{2} \mathrm{~g}^{-1}\right)$. The nitrogen adsorption-desorption isotherms for these samples are compared in Fig. S7. $\uparrow$ The Fe-derived sample exhibits the most dominant mesoporous feature, consistent with the largest tube size. Thus, the Fe-derived carbon nanotubes with largest diameter are expected to provide the largest number of active sites for the ORR with favorable mass transport.

While BET surface area determined by $\mathrm{N}_{2}$ adsorption is important to characterize porous catalysts, electrochemically accessible surface area $\left(S_{\mathrm{a}}\right)$ is more relevant for electrocatalysis, and was measured to determine the utilization of surface area available for the ORR. Fig. 6 shows CV curves for each sample in the absence of $\mathrm{O}_{2}$. These were used to compute the $S_{\mathrm{a}}$ in $0.5 \mathrm{M} \mathrm{H}_{2} \mathrm{SO}_{4}$ solution (a) and $0.1 \mathrm{M} \mathrm{NaOH}$ solution (b). The

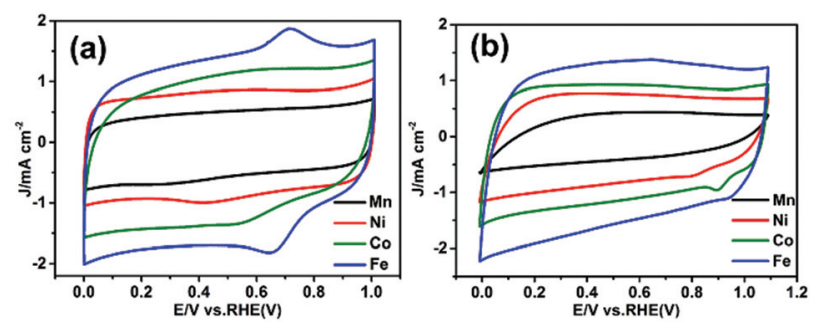

Fig. $6 \mathrm{CV}$ curves obtained at room temperature in $\mathrm{N}_{2}$-saturated $0.5 \mathrm{M}$ $\mathrm{H}_{2} \mathrm{SO}_{4}(\mathrm{a})$ and $0.1 \mathrm{M} \mathrm{NaOH}(\mathrm{b})$ at a rotation speed of $100 \mathrm{rpm}$. upper branch of the voltammograms between 0.2 and $0.6 \mathrm{~V}$ in acidic or alkaline solution is attributed to pseudocapacitance associated with the electrolyte-accessible surface area of the nanocarbon catalyst. Thus, the effective $S_{\mathrm{a}}\left(\mathrm{m}^{2} \mathrm{~g}^{-1}\right)$ can be deduced from the gravimetric double layer capacitance $C\left(\mathrm{~F} \mathrm{~g}^{-1}\right)$. $C$ can be represented as: ${ }^{45,46}$

$$
C=\frac{I}{v m}
$$

where $I$ is the current, $m$ is the electrode mass, and $v$ is the scan rate (here $20 \mathrm{mV} \mathrm{s}^{-1}$ ). The $S_{\mathrm{a}}$ value can then be determined as:

$$
S_{\mathrm{a}}=\frac{C}{C_{\mathrm{GC}}}
$$

where $C_{\mathrm{GC}}$ is the double layer capacitance $\left(\mathrm{F} \mathrm{m}^{-2}\right)$ of a glassy carbon electrode surface, typically $0.2 \mathrm{~F} \mathrm{~m}^{-2} .{ }^{42}$ The values of $S_{\mathrm{a}}$ calculated from eqn (1) and (2) are summarized in Table S1 $\uparrow$ for both acidic and alkaline electrolytes. Compared to other samples, the Fe-derived carbon nanotubes show the highest $S_{\mathrm{a}}$, reaching $419 \mathrm{~m}^{2} \mathrm{~g}^{-1}$ and $403 \mathrm{~m}^{2} \mathrm{~g}^{-1}$ in acidic and alkaline solutions, respectively. The values of $S_{\mathrm{a}}$ decreased in the same order, $\mathrm{Fe}>\mathrm{Co}>\mathrm{Ni}>\mathrm{Mn}$, in both electrolytes.

\section{Electrochemical activity for the ORR}

Electrocatalytic activity of the nanocarbon catalysts for the ORR was evaluated in both acidic and alkaline electrolytes using a RRDE at room temperature and a rotation speed of 900 rpm. Generally, TM-derived N-M-C catalysts exhibit improved ORR activity, relative to metal-free carbon catalysts. Thus, we did not compare with the poor catalytic activity of the sample prepared without any metal, but focus on comparing the results obtained using the different TMs. Fig. 7a and $b$ compare the steady-state ORR polarization curves measured in $0.5 \mathrm{M} \mathrm{H}_{2} \mathrm{SO}_{4}$ and $0.1 \mathrm{M} \mathrm{NaOH}$, respectively. Notably, in order to minimize the possible effects of post-treatment on ORR catalytic activity, these samples are not the final catalysts, but were only subject to the first heat treatment and the acid leaching step. At this synthesis stage, the different TMs indeed lead to significantly different catalytic activity for the ORR. In both acidic and alkaline media, the onset potential of the ORR for TM-derived carbon samples follows the order of $\mathrm{Fe}>\mathrm{Co}>\mathrm{Ni}>$ $\mathrm{Mn}$, indicating that the nature of the catalytically active sites varied with the metals used for synthesis. In particular, the most positive onset potential, measured with the Fe-derived sample, reached $0.89 \mathrm{~V}$, followed by Co- $(0.84 \mathrm{~V})$, Ni- $(0.60 \mathrm{~V})$, and $\mathrm{Mn}-(0.58 \mathrm{~V})$ derived samples. The Fe-derived sample also showed the most positive half-wave potential $\left(E_{1 / 2}\right)$ at $0.71 \mathrm{~V}$, indicating that it provided the largest number of active sites available for the ORR. Similarly, the Fe-derived catalyst also exhibited the highest activity in the alkaline solution, again showing the most positive onset and $E_{1 / 2}$ potentials.

Based on our previous effort to develop high-performance carbon-based NMPCs, a second heat treatment is able to remove the oxygen-containing functional groups and corrosive carbon species from catalysts, thereby further enhancing the 

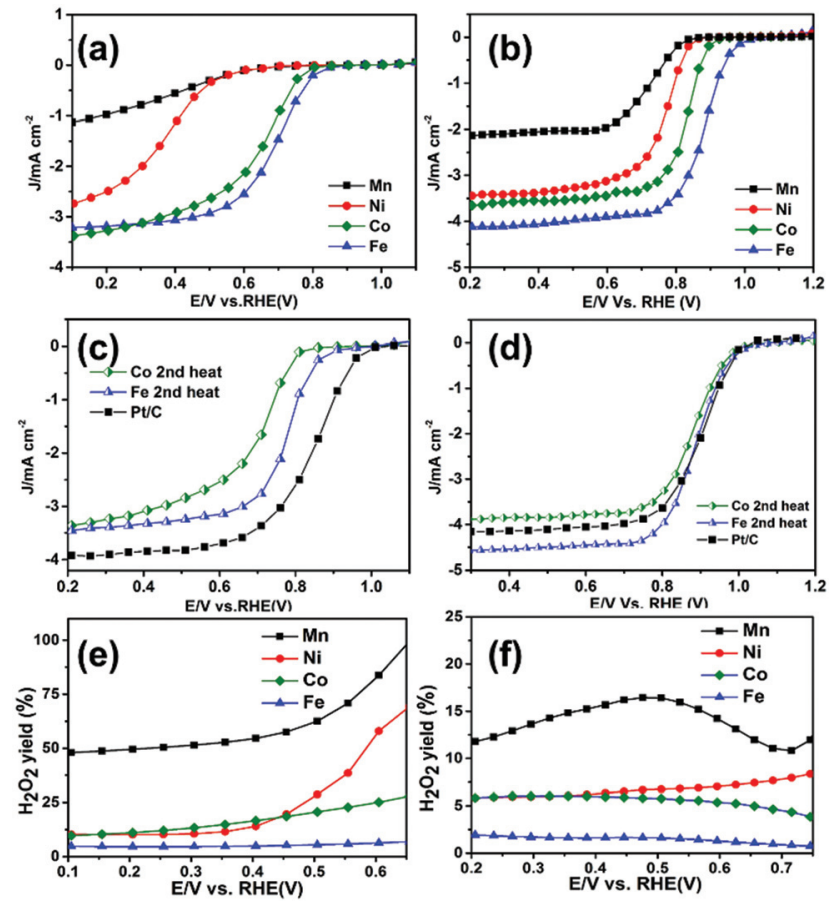

Fig. 7 Steady-state polarization plots of the ORR for the samples prepared using $\mathrm{Fe}, \mathrm{Co}, \mathrm{Ni}$ or $\mathrm{Mn}$, after the first heating treatment, in (a) $0.5 \mathrm{M}$ $\mathrm{H}_{2} \mathrm{SO}_{4}$ and (b) $0.1 \mathrm{M} \mathrm{NaOH}$. Final Co- and Fe-derived catalysts, after the second heat treatment, were further compared with $\mathrm{Pt} / \mathrm{C}$ reference in (c) acidic and (d) alkaline electrolytes. (electrolytes used for $\mathrm{Pt} / \mathrm{C}$ reference were $0.1 \mathrm{M} \mathrm{HClO}_{4}$ and $0.1 \mathrm{M} \mathrm{NaOH}$; loading: $20 \mathrm{\mu g} \mathrm{cm}^{-2}$ ). Peroxide yield in (e) acidic and ( $f$ ) alkaline electrolytes during the ORR. All of measurements were performed at a rotation speed of $900 \mathrm{rpm}$ and room temperature.

ORR activity. Thus, for the two most promising Fe- and Coderived catalysts, we applied a second heat treatment at $1000{ }^{\circ} \mathrm{C}$ in $\mathrm{N}_{2}$ for $3 \mathrm{~h}$. A comparison of ORR activities of these samples before and after the second heat treatment at a rotation rate of $900 \mathrm{rpm}$ is shown in ESI Fig. S8. $\uparrow$ Both Coderived and Fe-derived catalysts exhibited dramatically improved activity in both the kinetically-controlled and masstransfer controlled potential regions, indicating a significant increase in the number of active sites for the ORR. In particular, the onset potential of the Fe-derived catalyst was shifted from $0.89 \mathrm{~V}$ to $0.95 \mathrm{~V}$ in acidic solution. In the alkaline solution measurement, the onset potential was also positively shifted by $30 \mathrm{mV}$, to $1.05 \mathrm{~V}$, but the change was much smaller than in acidic solution. These results clearly show improved catalytic performance after the second heat-treatment. Notably, the difference in activity between Fe- and Co-based catalysts subjected to the second heating is much smaller in alkaline electrolyte, relative to acidic electrolyte. Once again, it is very likely that the active sites for the ORR in acid and alkaline media are different. The final Fe- and Co-derived carbon nanotube catalysts after the second heating treatment were further compared with the commercial $20 \mathrm{wt} \% \mathrm{Pt} / \mathrm{C}$ catalysts. ORR activities in acid and alkaline electrolytes are shown in Fig. 7c and d, respectively. Like other state-of-the-art nonpre- cious metal catalysts, in the more challenging acidic media, Coand Fe-based catalysts are still inferior to Pt/C. However, in the alkaline media, the ORR activities are quite comparable to, or even exceeded, that of the $\mathrm{Pt} / \mathrm{C}$, demonstrating their great promise to replace precious metals in alkaline fuel cells and metal-air batteries.

The high resolution XPS spectra of the $\mathrm{N}$ 1s region for the catalysts synthesized using $\mathrm{Fe}$ and Co before and after the second heat-treatment are shown in ESI Fig. S9 and Table S2. $\dagger$ After the second heat-treatment, the total $\mathrm{N}$ content of the Fe-derived catalyst was reduced from 4.49 at $\%$ to 2.93 at $\%$. However, the relative graphitic $\mathrm{N}$ content increased by around $6.5 \%$, relative to the pyridinic $\mathrm{N}$ content. In contrast, the second heat-treatment did not lead to a drop of total nitrogen content for the Co-derived catalyst, but reduced the relative graphitic $\mathrm{N}$ content. Comparing the high resolution XPS spectra of $\mathrm{Fe}$ and Co-derived catalysts in the $\mathrm{C}$ 1s region (ESI Fig. $\mathrm{S} 10 \dagger), \mathrm{C}-\mathrm{C}$ and $\mathrm{C}=\mathrm{O}$ peaks became narrower in both cases. This suggests an increased level of graphitization after the second heat treatment. Also, the total O content dropped significantly in both Fe and Co derived catalysts. Therefore, after the second heat treatment, both catalysts exhibited a higher degree of graphitization and lower concentration of inactive surface ligands, as indicated by the reduced O content. We conclude that those factors enhanced ORR performance in both $\mathrm{Fe}$ and Co derived catalysts. Notably, the reduced total $\mathrm{N}$ content does not result in a decrease of ORR activity for Fe-based catalysts. Once again, relative to total $\mathrm{N}$ content, achieving an optimal ratio of graphitic to pyridinic $\mathrm{N}$ is more important to ORR activity.

In addition to onset potential, the limiting current density also varied significantly between catalysts derived using different TMs. The Fe-derived catalyst showed the highest limiting current density. This can be attributed to two factors. First, its high electrochemically accessible surface area with mesoporosity provides efficient mass transfer within catalyst layers, thereby increasing limiting current. Second, the Federived catalyst showed the highest selectivity toward fourelectron reduction of $\mathrm{O}_{2}$ to $\mathrm{H}_{2} \mathrm{O}$ over two-electron reduction to $\mathrm{H}_{2} \mathrm{O}_{2}$, as indicated by results in Fig. 7e and $\mathrm{f}$. These show $\mathrm{H}_{2} \mathrm{O}_{2}$ yields in $0.5 \mathrm{M} \mathrm{H}_{2} \mathrm{SO}_{4}$ and $0.1 \mathrm{M} \mathrm{NaOH}$, respectively. Federived catalysts only yield $5 \%$ and $2 \%$ peroxide in the acidic and alkaline electrolytes, respectively. In contrast, the $\mathrm{Mn}$ derived sample showed low four-electron selectivity, with $50 \%$ and $15 \%$ peroxide yield in acid and alkaline electrolytes, respectively. The selectivity of Co and Ni-derived samples fell between those of Fe- and Mn-derived samples. This order was consistent with the order of their limiting current densities.

Based on current understanding along with the correlation of catalytic activity and physical properties, the ORR activity order of $\mathrm{Fe}>\mathrm{Co}>\mathrm{Ni}>\mathrm{Mn}$ was determined by differences in electrochemically accessible surface area and nitrogen doping. At present, the detailed nature of active sites in the $\mathrm{N}-\mathrm{M}-\mathrm{C}$ catalysts is still of debate, centered on the function of the transition metal during the catalyst synthesis. Some researchers have asserted that metals only catalyze nitrogen doping into 
graphitized carbon structures, and are not a part of the active sites for the ORR. However, increasing evidence suggests that the metal, especially $\mathrm{Fe}$, could directly participate in the active site for the ORR by coordinating with nitrogen or carbon. ${ }^{4-50}$ This controversy notwithstanding, catalytic activity was found to depend strongly on the catalyst morphology, which is related to the density of active sites, and mass transfer. These factors can be controlled in the catalyst synthesis process, through selection of the nitrogen precursor, transition metal, heating temperature, and support material. Here we clearly demonstrated that key morphology-related factors such as surface area, defect concentration in carbon nanostructures, and optimal nitrogen doping play important roles in improving overall catalyst performance. Compared to $\mathrm{Fe}$, Co, and $\mathrm{Ni}$, we show that Mn was much more effective in catalyzing the formation of perfect graphite-like carbon structures, as demonstrated by the sharp carbon (002) peak in XRD, the more negative binding energy in C 1s XPS, and the highly ordered structures visible in HR-TEM images. However, Mn failed to induce sufficient nitrogen doping to produce a highly active catalyst. The perfect graphitic structures with low nitrogen content produced with Mn resulted in the lowest ORR activity among the catalysts considered here. In contrast, a substantial concentration of defects and dislocations was identified in Febased carbon catalysts, which were the most active electrocatalysts. This supports the view that defects in the carbon nanotubes catalyzed by $\mathrm{Fe}$ are critical for achieving high ORR activity. In addition, Fe-based catalysts have the most favorable morphology, providing more active sites (high electrochemically active surface area) and efficient mass transfer (large-size tubes) for the ORR electrocatalysis. ${ }^{48-50}$

Notably, although Fe-derived carbon nanotube catalysts had the highest ORR activity, they had the lowest ratio of electrochemically accessible surface area to BET surface area among the four catalysts studied here. Thus, the Fe-derived carbon nanotube catalyst still has the greatest potential for further enhancement of ORR catalytic activity by further optimizing morphology and structure to increase the catalyst utilization, i.e. active surface area that is electrochemically accessible and, therefore, contributes to ORR activity.

\section{Conclusion}

Large-size and few-walled N-doped carbon nanotubes have emerged as a new type of high-performance nonprecious metal catalyst for the ORR. In this work, we build upon our previous effort to demonstrate a novel approach for fine-tuning the diameters of large-size carbon nanotubes by varying the TM used for catalyst preparation. Among studied metals, Fe, Co and $\mathrm{Ni}$ are very effective in catalyzing formation of carbon tubes with different sizes following the order Fe $(110 \mathrm{~nm})>$ Co $(60 \mathrm{~nm})>\mathrm{Ni}(40 \mathrm{~nm})$. Rather than tubes, Mn yields cage-like nanocarbon with a relatively high degree of graphitization, low concentration of defects, and low nitrogen content. In contrast, substantial numbers of dislocations and defects were found in Fe-based bamboo-like carbon nanotubes. Meanwhile, ORR activity measured with these nanocarbon samples in both acid and alkaline electrolytes followed the same sequence, $\mathrm{Fe}>\mathrm{Co}>\mathrm{Ni}>\mathrm{Mn}$ in terms of their onset/half-wave potentials, four-electron selectivity, and limiting current densities. Notably, the critical second heat-treatment during the synthesis reduces the ORR activity difference between Co- and Fe-based catalysts, and this difference was much smaller in alkaline media than that in acid. These results strongly suggest that the active sites for the ORR in acid and alkaline media are significantly different.

This work establishes a synthesis-morphology-property relationship that can provide a basis for further catalyst improvements. Compared with other nanocarbons, the unique large-size and few-walled carbon nanotubes derived from $\mathrm{Fe}$ have the largest surface area, both in terms of traditional BET surface area and the more relevant electrochemically accessible surface area. This favorable morphology provides the highest number of active sites for the ORR. The level of nitrogen doping was consistent among these nanotube samples, which allowed us to specifically study the morphology-dependence of the ORR activity. Although the intrinsic activity of the catalyst may be associated with the nature of likely $\mathrm{M}-\mathrm{N}$ moieties ( $\mathrm{Fe}-\mathrm{N}$ or $\mathrm{Co}-\mathrm{N})$, morphology clearly also plays an important role in governing the catalyst activity. This work provides new insights into the origins of catalytic activity, which can be used to design and synthesize advanced nanocarbon catalysts for electrochemical energy conversion.

\section{Acknowledgements}

The authors gratefully acknowledge financial support from the New York State Center of Excellence in Materials Informatics (M.T.S.) and startup funds from the University at Buffalo (SUNY) along with U.S. Department of Energy, Fuel Cell Technologies Office (FCTO) Incubator Program (DE-EE0006960) and National Science Foundation (CBET-1511528) (G.W.).

\section{Notes and references}

1 A. Rabis, P. Rodriguez and T. J. Schmidt, ACS Catal., 2012, 2, 864-890.

2 Y. J. Wang, J. Qiao, R. Baker and J. Zhang, Chem. Soc. Rev., 2013, 42, 5768-5787.

3 F. Jaouen, E. Proietti, M. Lefèvre, R. Chenitz, J.-P. Dodelet, G. Wu, H. T. Chung, C. M. Johnston and P. Zelenay, Energy Environ. Sci., 2011, 4, 114-130.

4 C. Zhang, L. Xu, N. Shan, T. Sun, J. Chen and Y. Yan, ACS Catal., 2014, 4, 1926-1930.

5 B. J. Kim, D. U. Lee, J. Wu, D. Higgins, A. Yu and Z. Chen, J. Phys. Chem. C, 2013, 117, 26501-26508.

6 Z. Chen, D. Higgins, A. Yu, L. Zhang and J. Zhang, Energy Environ. Sci., 2011, 4, 3167-3192. 
7 W. Zhou, J. Wu and H. Yang, Nano Lett., 2013, 13, 28702874.

8 Y. Kang, J. B. Pyo, X. Ye, R. E. Diaz, T. R. Gordon, E. A. Stach and C. B. Murray, ACS Nano, 2012, 7, 645-653.

9 N. Ramaswamy, U. Tylus, Q. Jia and S. Mukerjee, J. Am. Chem. Soc., 2013, 135, 15443-15449.

10 Z. Chen, D. Higgins, A. Yu, L. Zhang and J. Zhang, Energy Environ. Sci., 2011, 4, 3167-3192.

11 X. Wang, X. Liu, D. Yin, Y. Ke and M. T. Swihart, Chem. Mater., 2015, 27, 3378-3388.

12 X. Wang, Y. Ke, H. Pan, K. Ma, Q. Xiao, G. Wu and M. T. Swihart, ACS Catal., 2015, 5, 2534-2540.

13 G. Wu and P. Zelenay, Acc. Chem. Res., 2013, 46, 1878-1889.

14 G. Wu, K. L. More, C. M. Johnston and P. Zelenay, Science, 2011, 332, 443-447.

15 Q. Li, R. Cao, J. Cho and G. Wu, Adv. Energy Mater., 2014, 4, 1301415.

16 G. Wu, K. L. More, P. Xu, H.-L. Wang, M. Ferrandon, A. J. Kropf, D. J. Myers, S. Ma, C. M. Johnston and P. Zelenay, Chem. Commun., 2013, 49, 3291-3293.

17 R. Cao, R. Thapa, H. Kim, X. Xu, M. G. Kim, Q. Li, N. Park, M. Liu and J. Cho, Nat. Commun., 2013, 4, 2076.

18 Q. Li, G. Wu, D. A. Cullen, K. L. More, N. H. Mack, H. T. Chung and P. Zelenay, ACS Catal., 2014, 4, 3193-3200.

19 Q. Li, H. Pan, D. Higgins, R. Cao, G. Zhang, H. Lv, K. Wu, J. Cho and G. Wu, Small, 2015, 11, 1443-1452.

20 Q. Li, P. Xu, W. Gao, S. Ma, G. Zhang, R. Cao, J. Cho, H. L. Wang and G. Wu, Adv. Mater., 2014, 26, 1378-1386.

21 M. Quintana, H. Traboulsi, A. Llanes-Pallas, R. Marega, D. Bonifazi and M. Prato, ACS Nano, 2012, 6, 23-31.

22 D. B. Shinde, J. Debgupta, A. Kushwaha, M. Aslam and V. K. Pillai, J. Am. Chem. Soc., 2011, 133, 4168-4171.

23 Z. Chen, D. Higgins, H. Tao, R. S. Hsu and Z. Chen, J. Phys. Chem. C, 2009, 113, 21008-21013.

24 P. H. Matter, L. Zhang and U. S. Ozkan, J. Catal., 2006, 239, 83-96.

25 T. Palaniselvam, B. P. Biswal, R. Banerjee and S. Kurungot, Chem. - Eur. J., 2013, 19, 9335-9342.

26 G. Wu, M. Nelson, S. Ma, H. Meng, G. Cui and P. K. Shen, Carbon, 2011, 49, 3972-3982.

27 Y. Tang, B. L. Allen, D. R. Kauffman and A. Star, J. Am. Chem. Soc., 2009, 131, 13200-13201.

28 Z. Wen, S. Ci, F. Zhang, X. Feng, S. Cui, S. Mao, S. Luo, Z. He and J. Chen, Adv. Mater., 2012, 24, 1399-1404.

29 F. Banhart, Nanoscale, 2009, 1, 201-213.

30 M. He, S. Zhou, J. Zhang, Z. Liu and C. Robinson, J. Phys. Chem. B, 2005, 109, 9275-9279.
31 C. Shan, W. Zhao, X. L. Lu, D. J. O’Brien, Y. Li, Z. Cao, A. L. Elias, R. Cruz-Silva, M. Terrones and B. Wei, Nano Lett., 2013, 13, 5514-5520.

32 Z. Yang, Y. Xia and R. Mokaya, Chem. Mater., 2005, 17, 4502-4508.

33 K. Gong, F. Du, Z. Xia, M. Durstock and L. Dai, Science, 2009, 323, 760-764.

34 Y. Tang, S. C. Burkert, Y. Zhao, W. A. Saidi and A. Star, J. Phys. Chem. C, 2013, 117, 25213-25221.

35 F. Bonaccorso, Z. Sun, T. Hasan and A. C. Ferrari, Nat. Photonics, 2010, 4, 611-622.

36 G. Wu, C. M. Johnston, N. H. Mack, K. Artyushkova, M. Ferrandon, M. Nelson, J. S. Lezama-Pacheco, S. D. Conradson, K. L. More and D. J. Myers, J. Mater. Chem., 2011, 21, 11392-11405.

37 V. Nallathambi, J.-W. Lee, S. P. Kumaraguru, G. Wu and B. N. Popov, J. Power Sources, 2008, 183, 34-42.

38 G. Wu, Z. Chen, K. Artyushkova, F. H. Garzon and P. Zelenay, ECS Trans., 2008, 16, 159-170.

39 D. Usachov, A. Fedorov, O. Vilkov, B. Senkovskiy, V. K. Adamchuk, L. V. Yashina, A. A. Volykhov, M. Farjam, N. I. Verbitskiy and A. Grüneis, Nano Lett., 2014, 14, 49824988.

40 Q. He, Q. Li, S. Khene, X. Ren, A. Bueno-López and G. Wu, J. Phys. Chem. C, 2013, 117, 8697-8707.

41 G. Wu, D. Li, C. Dai, D. Wang and N. Li, Langmuir, 2008, 24, 3566-3575.

42 J. D. Wiggins-Camacho and K. J. Stevenson, J. Phys. Chem. C, 2011, 115, 20002-20010.

43 T. Sharifi, G. Hu, X. Jia and T. Wågberg, ACS Nano, 2012, 6, 8904-8912.

44 G. Wu, N. H. Mack, W. Gao, S. Ma, R. Zhong, J. Han, J. K. Baldwin and P. Zelenay, ACS Nano, 2012, 6, 9764-9776.

45 D. C. Higgins, M. A. Hoque, F. Hassan, J.-Y. Choi, B. Kim and Z. Chen, ACS Catal., 2014, 4, 2734-2740.

46 G. Wu, Y.-S. Chen and B.-Q. Xu, Electrochem. Commun., 2005, 7, 1237-1243.

47 G. Wu, R. Swaidan, D. Li and N. Li, Electrochim. Acta, 2008, 53, 7622-7629.

48 E. F. Holby, G. Wu, P. Zelenay and C. D. Taylor, J. Phys. Chem. C, 2014, 118, 14388-14393.

49 M. Ferrandon, A. J. Kropf, D. J. Myers, K. Artyushkova, U. Kramm, P. Bogdanoff, G. Wu, C. M. Johnston and P. Zelenay, J. Phys. Chem. C, 2012, 116, 16001-16013.

50 M. Ferrandon, X. Wang, A. J. Kropf, D. J. Myers, G. Wu, C. M. Johnston and P. Zelenay, Electrochim. Acta, 2013, 110, 282-291. 